\title{
Cerebral Venous Thrombosis as a First Vaso- Occlusive Crisis in a Sickle Cell Disease Patient
}

\author{
Eman Almusallam, Eman Alhassan, Ali Alsaeed, Aqeela Alhashim, Mohammed Alhazzaa* \\ Department of Neurology, National Neuroscience Institute, Saudi Arabia
}

Submission: March 12, 2019; Published: March 26, 2019

*Corresponding author: Mohammed Alhazzaa, Department of Neurology, National Neuroscience Institute, King Fahad Medical City, Riyadh, Saudi Arabia

\section{Abstract}

Sickle Cell Disease (SCD) is a well-known precipitant of vascular occlusions when triggers of SCD crisis are active. This process commonly impacts the arterial circulation in different organs. SCD has not been recognized as a leading cause of Cerebral Venous Thrombosis (CVT) and the crisis does not typically start within the venous system. In this report, we present a case of SCD patient presenting with venous thrombosis as an initial vascular attack.

Keywords: Sickle cell disease; Venous thrombosis; Venous system; Thrombosis; Intracerebral hemorrhage; Emergency department; Blood count Abbrevations: SCD: Sickle Cell Disease; ICH: Intracerebral Hemorrhage; CVT: Cerebral Venous Thrombosis

\section{Introduction}

Cerebrovascular complication of sickle cell anemia is well established in the literature. However, the main focus has been directed toward arterial vaso-occlusive crisis and other rare associated arteriopathies such as Moyamoya syndrome [1,2]. Intracerebral Hemorrhage (ICH) is a known complication of SCD and it typically happens in adult patients due to different reasons such as aneurysmal formation [3]. Recently, a number of reports have been published about venous thrombosis occurrence in the setting of SCD [4-7]. This probably reflects the nature of the disease and on the other hand the advancement in diagnostic methods. Cerebral Venous Thrombosis (CVT) can cause ICH. This might implicate that CVT could be a potential mechanism of ICH among SCD patients where provoked or unprovoked blood flow abnormalities are likely to generate thrombosis within veins similar to the arterial crisis. In this brief encounter, we will discuss venous thrombosis in a young patient with sickle cell anemia who never had any prior vascular crisis.

\section{Case Report}

An 18-year-old right-handed male presented to the Emergency Department (ED) with right-sided weakness. He is known to have sickle cell anemia on folic acid. He was a smoker. He had no history of previous neurological manifestations or systemic vaso-occlusive crisis. His physical examination revealed aphasia and right-sided hemiplegia. During ED visit, his consciousness level deteriorated and he required intubation. His CT scan of the brain revealed a left temporal lobe large hemorrhage with significant vasogenic edema and midline shift (Figure 1). He required immediate decompressive hemicraniectomy. Intraoperatively, a thrombosis of the left vein of Labbe was noted. Although Magnetic Resonance Venography (MRV) showed patent main venous sinuses, a four-vessel cerebral angiography demonstrated the paucity of the left convexity cortical veins, confirming a cortical and/or deep venous thrombosis (Figure 2).

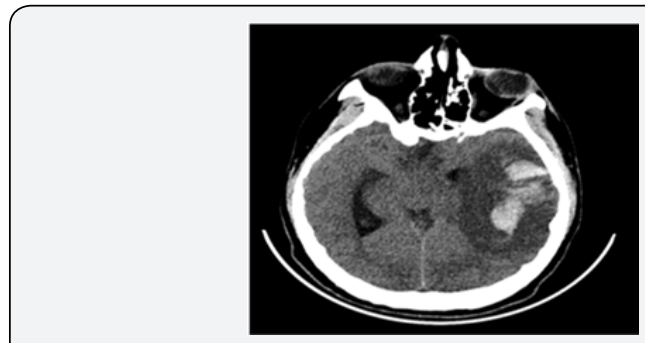

Figure 1: CT scan of the brain showing a left temporal lobe large hemorrhage.

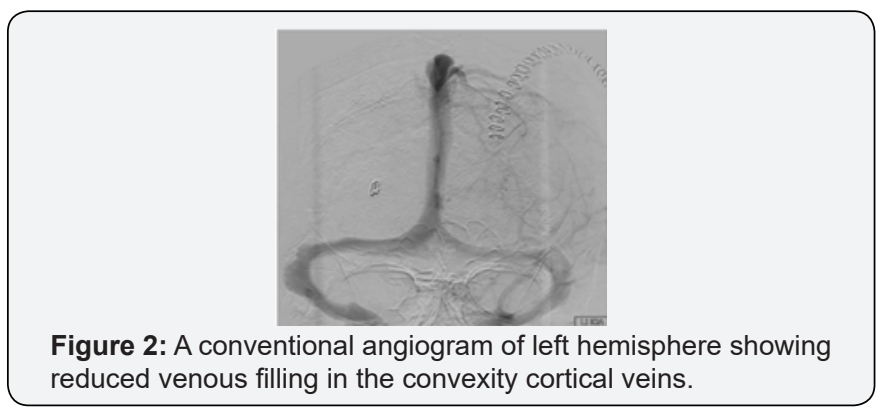


His Complete Blood Count revealed hemoglobin (Hb) (8.7) and platelets (306). He had normal thrombophilia testing including antiphospholipid antibodies, Factor V Leiden mutation, antithrombin, protein $\mathrm{C}$, and protein S level. Hemoglobin electrophoresis showed $\mathrm{HbS} 73 \%$ and $\mathrm{Hb}$ A $20 \%$. He was evaluated by Hematology and started on hydroxyurea $500 \mathrm{mg}$ twice daily and exchange transfusion where $\mathrm{Hb} \mathrm{S}$ was lowered to $26 \%$. He had smooth hospital course with slow recovery. Then, he required extensive rehabilitation where he showed significant improvement. He was discharged on aspirin $81 \mathrm{mg}$ daily and hydroxyurea $1000 \mathrm{mg}$ daily. He received multiple exchange transfusion. After two years of follow up, there has been no recurrence of any vascular crisis.

\section{Discussion}

Sickle cell disease is prevalent in some regions of Saudi Arabia where it has unique presentations involving different systems. This hematological condition produces its symptoms following a complicated pathological cascade involving disfigured sickled red blood cells, endothelium, and coagulation system [1,2]. As a result, hyper viscosity and coagulopathy promote occlusive vasculopathy, which is considered the most serious hallmark of this disease. Hence, SCD is associated with increased risk of ischemic strokes secondary to acute thrombosis and other known vasculopathies such as Moyamoya pattern [1,2]. Although Intracerebral hemorrhage (ICH) is less commonly seen, it is considered as another vascular complication of SCD $[1,3]$. Adults with SCD are more likely to develop ICH due to unclear mechanisms. Some suggested associated aneurysms and Moyamoya disease as potential etiologies [3], but those do not provide a satisfactory explanation in several ICH cases. There have been few reports about CVT in SCD after certain precipitants [4-7], and CVT can lead to a brain hemorrhage. In this case, we postulate a new pathophysiological concept underlying this devastating disease in which CVT could be a variant of occlusive disease among SCD patients where it can be the first presenting vascular crisis. Therefore, we suggest a similar sickling mechanism that may predominantly affect venous system causing acute occlusion. Arterial infarctions are well understood in SCD and easy to diagnose, however, CVT might have been overlooked in cases of ICH. As a result, CVT should be diligently sought since it can be a potential cause of ICH. In our case, intraoperative recognition of the venous thrombus was a key in diagnosis although MR venogram was not suggestive. This also raises another observation of whether SCD selectively involves the deep venous system which adds another layer of complexity in identifying thrombosis with the use of regular imaging modalities. Hence, catheter cerebral angiography would be of great help in diagnosis.

There are reported precipitating factors that might have played a role in the development of CVT in patients with SCD [5-
7]. Dehydration and infection are common provoking factors for the occlusive crisis in SCD. Our patient had no definite triggers apart from being a smoker, which probably contributed to increased blood viscosity. He has no family history of thrombosis and his thrombophilia workup is unremarkable. This may also add to the notion of CTV as a potential occlusive variant. There have been other factors reported as possible triggers of CVT in SCD patients such as exchange transfusion and following hydroxyurea initiation $[4,5]$. CVT in those cases was attributed to rapid correction of hemoglobin level. However, this could be a coincidence and we don't have a strong evidence to reach a level of association or causation. Our patient had no vascular exacerbation after exchange transfusion or use of hydroxyurea.

In conclusion, we are presenting a case of venous thrombosis among adult sickle cell patient as a first clinical vascular attack. CVT might be underestimated condition in SCD and therefore missed in patients with acute ICH, unless specifically sought with advanced imaging modalities. Diagnosis certainty will impact the treatment plan. There is growing evidence that supports the presence of a venous variant of acute occlusive crisis. However, there are several questions remain unanswered. It is unclear if this venous variant has unique provoking factors and pathogenesis. It is also uncertain whether exchange transfusion is efficacious in preventing future venous events as compared to the arterial variant. Further studies are required to recognize SCD patients at high risk of CVT and identify ideal diagnostic and treatment options.

\section{References}

1. Steven H Yale, Nahed Nagib (2000) Approach to the Vaso-occlusive Crisis in Adults with Sickle Cell Disease. Am Fam Physician 61(5): 1349-1356.

2. Zohreh Rahimi, Abbas Parsian, et al. (2011) Sickle Cell Disease and Venous Thromboembolism. Mediterr J Hematol Infect Dis 3(1): e2011024.

3. Adekile A (2015) Risk of cerebral hemorrhage in children with sickle cell disease. Dev Med Child Neurol 57(2):116-117.

4. Chetan Y Dhoble, Neelima Saoji (2015) Cerebral Venous Thrombosis in a 35-Year-Old with Undiagnosed Sickled Cell Disease: A Case Report. Med Sci Case Rep 2: 29-32.

5. Kodadhala V, Conyette L, Ramcharan K, Daisley H (2014) Dural Venous Sinus Thrombosis in Sickle Cell Disease in a West Indian. West Indian Med J 63(7): 811-812.

6. Ciurea SO, Thulborn KR, Gowhari M (2006) Dural Venous Sinus Thrombosis in a Patient with Sickle Cell Disease: Case Report and Literature Review. Am J Hematol 81:290-293.

7. Sidani CA, Ballourah W, El Dassouki M, Muwakkit S, Dabbous I, et al. (2008) Venous sinus thrombosis leading to stroke in a patient with sickle cell disease on hydroxyurea and high hemoglobin levels: treatment with thrombolysis. Am J Hematol 83(10): 818-820. 
(C) This work is licensed under Creative BY DOI: 10.19080/OAJNN.2019.10.555790

\section{Your next submission with Juniper Publishers will reach you the below assets}

- Quality Editorial service

- Swift Peer Review

- Reprints availability

- E-prints Service

- Manuscript Podcast for convenient understanding

- Global attainment for your research

- Manuscript accessibility in different formats ( Pdf, E-pub, Full Text, Audio)

- Unceasing customer service

Track the below URL for one-step submission https://juniperpublishers.com/online-submission.php 